\title{
Association Between Hopelessness And Suicidal Ideation In Iranian Medical Students: A Cross-Sectional Study
}

\author{
Mohammad Hossein Sadeghian', Farnaz Etesam², Amin Nakhostin-Ansari ${ }^{3}$, Samaneh Akbarpour ${ }^{4}$, Mitra Akhlaghi $^{5}$ \\ ${ }^{1}$ Department of Forensic Medicine, School of Medicine, Tehran University of Medical Sciences, 2 Psychosomatic medicine research center, Imam \\ Khomeini Hospital, Tehran University of Medical Sciences, ${ }^{3}$ Sports Medicine Research Center, Neuriscoeince Institute, 4 Occupational Sleep Research \\ Center, Baharloo Hospital, Tehran University of Medical Sciences, ${ }^{5}$ Legal Medicine Research Center, Legal Medicine Organization \\ Keywords: medical education, suicidal ideation, hopelessness \\ https://doi.org/10.52965/001c.27579
}

\section{Health Psychology Research}

Vol. 9, Issue 1, 2021

\section{Background and Objectives}

There are limited studies regarding suicidal ideation among Iranian medical students. We aimed to evaluate the prevalence of suicidal ideation and its association with hopelessness among Tehran University of Medical Sciences (TUMS) medical students.

\section{Methods}

We designed a cross-sectional study conducted in TUMS in 2018. We developed a questionnaire consisting of three parts; the Beck Hopelessness Scale (BHS), four questions regarding suicidal ideation, and questions regarding demographic characteristics. We used the available sampling technique and sent the questionnaire to 517 medical students of TUMS.

\section{Results}

In total, 224 medical students completed and sent back the questionnaire (response rate $=43.32 \%)$. Participants' mean age was $22.68(\mathrm{SD}=3.38)$ years, and 140 participants (62.5\%) were female. One hundred seven students (47.76\%) had mild, 58 (25.89\%) had moderate, and 13 (5.8\%) had severe hopelessness. Males, senior students, and dissatisfied students with their academic performance experienced more severe hopelessness $(\mathrm{P}<0.05)$. Thirty-six participants $(16.07 \%)$ had suicidal ideation. After adjusting for age, gender, marital status, and student's satisfaction with their academic performance, BHS total score was independently associated with suicidal ideation $(\mathrm{OR}=1.29,95 \%$

$\mathrm{CI}=1.14-1.46, \mathrm{P}<0.0001$ )

\section{Conclusion}

The prevalence of suicidal ideation and hopelessness is relatively high among Iranian medical students. Students with more severe hopelessness are at higher risk of suicidal ideation, and evaluating hopelessness among medical students can be used to screen medical students at risk of suicidal ideation.

\section{INTRODUCTION}

Suicide is one of the common causes of mortality worldwide, with a global mortality rate of $1.4 \% .{ }^{1}$ The number of deaths from suicide has increased in recent years, and annually about 800000 people lose their lives because of suicide. ${ }^{2}$ Mortality from suicide is highest in people aged be- tween 15 to 29 years. ${ }^{1}$ A similar trend has been seen in young adults' suicide rate, which has increased in the past few years. ${ }^{3}$ In Iran, suicide mortality has increased from 0.2 to 5 per 100000 people between 1991 and $2010 .{ }^{4}$

Several factors, such as age, gender, socioeconomic status, and history of mental disorders, have associations with suicide mortality. ${ }^{1}$ The suicidal rate is higher in people with specific occupations, such as health care workers. ${ }^{5}$ Suicidal

\footnotetext{
a Corresponding author:

Mitra Akhlaghi

Phone number: +982166405588

Email: mitraakhlaghi@yahoo.com

Department of Forensic Medicine, School of Medicine, Tehran University of Medical Sciences, Tehran, Iran
} 
ideation and suicidal attempt are more prevalent among physicians, especially among general practitioners than the general population. ${ }^{6}$ The prevalence of mental disorders is not higher in students who enter medical school than other students $^{7}$; however, the risk of suicidal ideation increases in senior medical students. ${ }^{8}$ Hopelessness, guilt, the feeling of rejection, obsessive-compulsive disorder (OCD), burnout, depression, stress, and anxiety may all have associations with suicidal ideation among medical students. ${ }^{9-12}$

Suicidal ideation is one of the risk factors for attempting suicide. People with psychological disorders and suicidal ideation should receive proper treatment. ${ }^{13}$ Unfortunately, it seems that medical students do not receive enough treatment for their mental disorders. In a systematic review, Puthran et al. found that only $12.9 \%$ of medical students with depressive symptoms seek treatment. ${ }^{14}$ Medical students' under treatment for mental health issues may be one risk factor for a high suicidal rate among this group of people as mental health services may help people with suicidal ideations. ${ }^{15}$

Although the overall suicidal rate is lower in developing countries such as Iran, ${ }^{16}$ previous studies have shown that between $7.58 \%$ to $11.3 \%$ of Iranian university students had suicidal studies. ${ }^{17,18}$ A study by Mohammadinia et al. revealed that $26.4 \%$ of nursing, midwifery, and medical emergency students had suicidal ideations. ${ }^{19}$ In a study on medical students of Zahedan University of Medical Sciences, $17 \%$ of medical students had suicidal ideation, which is relatively high. ${ }^{20}$ Also, $7.2 \%$ of medical students had high-risk suicidal ideation, which is concerning. ${ }^{20}$

To summarize, the suicidal rate is higher among medical students and physicians compared to the general population. As suicidal ideation is a risk factor for a suicidal attempt, it is important to identify people with suicidal ideation as they may benefit from psychological services. There are only limited studies on suicidal ideation among Iranian medical students. This study aimed to evaluate the prevalence of suicidal ideation among medical students of Tehran University of Medical Sciences (TUMS) and evaluate the association between hopelessness and suicidal ideation in this group of people.

\section{MATERIALS AND METHODS}

This study was conducted as a cross-sectional study evaluating hopelessness and suicidal ideation among TUMS medical students in the 2018-2019 academic year. The ethics committee of TUMS approved the study protocol with the ethical code of IR.TUMS.MEDICINE.REC.1397.428IR.

\section{PARTICIPANTS}

At the time of the study, about 2000 medical students were studying in TUMS in different medical education stages, including basic sciences, the physiopathology of diseases, clerkship, and internship. Considering $\alpha=0.05, \mathrm{P}=0.057$, and $d=0.02$, we targeted a sample size of 517 medical students. We obtained our sample using the available sampling technique. The study aims and objectives were explained to the students, and if they were interested in participating in the study, they were given the questionnaire. Also, written consent was obtained from students who participated in the study. Students who did not give consent to participate in the study were excluded.

\section{QUESTIONNAIRES}

The questionnaire consisted of demographic and educational characteristics, Beck Hopelessness Scale (BHS), and suicidal ideation questions.

\section{DEMOGRAPHIC AND EDUCATIONAL STATUS}

In this part, students were asked about their gender, age, marital status, years of education in the university, accommodation status, smoking, and self-satisfaction with academic performance.

\section{BHS}

BHS is designed by Becket al. to evaluate pessimism and hopelessness. This questionnaire consists of 20 statements, and each statement can be answered by true or false. In nine statements, one score is dedicated to choosing "false." In eleven statements, one score is dedicated to choosing "true." The total score is the sum of all items scores and is calculated out of 20. Higher scores are indicative of more severe hopelessness. ${ }^{21}$ BHS's total scores of 0 to 3 are interpreted as normal, 4 to 8 as mild hopelessness, 9 to 14 as moderate hopelessness, and greater than 14 as severe hopelessness. ${ }^{22}$ BHS is translated to Persian, and its' Persian version is proven to be reliable (Cronbach's alpha=0.87) and valid tool for evaluating hopelessness among Iranian people. ${ }^{23,24}$ In the current study, we used the Persian version of BHS to evaluate hopelessness among medical students.

\section{SUICIDAL IDEATION}

The general health questionnaire (GHQ) is designed by Goldberg et al. consisted of 28 questions in four domains; somatic symptoms, anxiety and insomnia, social dysfunction, and depression. ${ }^{25} \mathrm{GHQ}$ has been translated to Persian and is proven reliable (Cronbach's alpha=0.92) and a valid tool for evaluating psychological issues in Iranian people. ${ }^{26,27}$ We used four questions from Persian GHQ to assess suicidal ideation. The first two questions were, "Have you ever felt that life is not worth living?" and "Have you ever found yourself wishing that you were away from it all?" These two questions could be answered by four options on a Likert scale, not at all (1), no more than usual (2), rather more than usual (3), and much more than usual (4). Other questions were, "Have you ever had thoughts of the possibility that you might do away with yourself?" and "Have you ever found the idea of taking your own life coming into your mind?" Respondents could choose one of the following options on a Likert scale for these questions; definitely not (1), I do not think so (2), has crossed my mind(3), and definitely has (4). Scores of 3 or 4 for each of these questions were considered having suicidal ideation. ${ }^{28}$

\section{STATISTICAL ANALYSIS}

Number and percentage were calculated for categorical 
Table 1. Hopelessness in medical students based on demographic characteristics

\begin{tabular}{|c|c|c|c|c|c|c|c|}
\hline \multirow{2}{*}{\multicolumn{2}{|c|}{ Variable }} & \multirow[t]{2}{*}{ Total } & \multicolumn{4}{|c|}{ Hopelessness } & \multirow[t]{2}{*}{ P-value } \\
\hline & & & $\begin{array}{l}\text { Normal } \\
(n=46)\end{array}$ & $\begin{array}{c}\text { Mild } \\
(n=107)\end{array}$ & $\begin{array}{l}\text { Moderate } \\
(n=58)\end{array}$ & $\begin{array}{l}\text { Severe } \\
(n=13)\end{array}$ & \\
\hline \multicolumn{2}{|l|}{ Age } & $\begin{array}{l}22.68 \\
(3.38)\end{array}$ & $\begin{array}{l}22.08 \\
(2.42)\end{array}$ & $\begin{array}{l}22.41 \\
(2.29)\end{array}$ & $\begin{array}{l}23.29 \\
(5.09)\end{array}$ & $\begin{array}{l}24.38 \\
(3.68)\end{array}$ & 0.062 \\
\hline \multirow[t]{2}{*}{ Gender } & Male & $\begin{array}{c}84 \\
(37.5 \%)\end{array}$ & $\begin{array}{c}11 \\
(13.1 \%)\end{array}$ & $\begin{array}{c}44 \\
(52.4 \%)\end{array}$ & $\begin{array}{c}23 \\
(27.4 \%)\end{array}$ & $\begin{array}{c}6 \\
(7.1 \%)\end{array}$ & \multirow[t]{2}{*}{0.033} \\
\hline & Female & $\begin{array}{c}140 \\
(62.5 \%)\end{array}$ & $\begin{array}{c}35 \\
(25 \%)\end{array}$ & $\begin{array}{c}63 \\
(45 \%)\end{array}$ & $35(25 \%)$ & $7(5 \%)$ & \\
\hline \multirow[t]{2}{*}{ Marital Status } & Married & $\begin{array}{c}27 \\
(12.1 \%) \\
\end{array}$ & $\begin{array}{c}4 \\
(14.8 \%) \\
\end{array}$ & $\begin{array}{c}17 \\
(63 \%)\end{array}$ & $5(18.5 \%)$ & $\begin{array}{c}1 \\
(3.7 \%) \\
\end{array}$ & \multirow[t]{2}{*}{0.432} \\
\hline & $\begin{array}{l}\text { Single/ } \\
\text { separated/ } \\
\text { divorced }\end{array}$ & $\begin{array}{c}197 \\
(87.9 \%)\end{array}$ & $\begin{array}{c}42 \\
(21.3 \%)\end{array}$ & $\begin{array}{c}90 \\
(45.7 \%)\end{array}$ & $\begin{array}{c}53 \\
(26.9 \%)\end{array}$ & $\begin{array}{c}12 \\
(6.1 \%)\end{array}$ & \\
\hline \multirow[t]{2}{*}{$\begin{array}{l}\text { Years of education in } \\
\text { university }\end{array}$} & $\begin{array}{c}\text { First/ second } \\
\text { year }\end{array}$ & $\begin{array}{c}79 \\
(35.3 \%)\end{array}$ & $\begin{array}{c}22 \\
(27.8 \%)\end{array}$ & $\begin{array}{c}39 \\
(49.4 \%)\end{array}$ & $\begin{array}{c}16 \\
(20.3 \%)\end{array}$ & $\begin{array}{c}2 \\
(2.5 \%)\end{array}$ & \multirow[t]{2}{*}{0.046} \\
\hline & $\begin{array}{l}\text { Third or } \\
\text { higher }\end{array}$ & $\begin{array}{c}145 \\
(64.7 \%) \\
\end{array}$ & $\begin{array}{c}24 \\
(16.5 \%) \\
\end{array}$ & $\begin{array}{c}68 \\
(46.9 \%) \\
\end{array}$ & $42(29 \%)$ & $\begin{array}{c}11 \\
(7.6 \%) \\
\end{array}$ & \\
\hline \multirow[t]{2}{*}{ Accommodation status } & Home & $\begin{array}{c}92 \\
(41.1 \%) \\
\end{array}$ & $\begin{array}{c}24 \\
(26.1 \%) \\
\end{array}$ & $\begin{array}{c}36 \\
(39.1 \%) \\
\end{array}$ & $\begin{array}{c}25 \\
(27.2 \%) \\
\end{array}$ & $\begin{array}{c}7 \\
(7.6 \%) \\
\end{array}$ & \multirow[t]{2}{*}{0.086} \\
\hline & Dormitory & $\begin{array}{c}132 \\
(58.9 \%) \\
\end{array}$ & $\begin{array}{c}22 \\
(16.7 \%) \\
\end{array}$ & $\begin{array}{c}71 \\
(53.8 \%) \\
\end{array}$ & $33(25 \%)$ & $\begin{array}{c}6 \\
(4.5 \%) \\
\end{array}$ & \\
\hline \multirow[t]{2}{*}{ Smoking } & No & $\begin{array}{c}194 \\
(86.6 \%) \\
\end{array}$ & $\begin{array}{c}43 \\
(22.2 \%) \\
\end{array}$ & $\begin{array}{c}91 \\
(46.9 \%) \\
\end{array}$ & $\begin{array}{c}51 \\
(26.3 \%) \\
\end{array}$ & $\begin{array}{c}9 \\
(4.6 \%) \\
\end{array}$ & \multirow[t]{2}{*}{0.123} \\
\hline & Yes & $\begin{array}{c}30 \\
(13.4 \%) \\
\end{array}$ & $3(10 \%)$ & $\begin{array}{c}16 \\
(53.4 \%) \\
\end{array}$ & $7(23.3 \%)$ & $\begin{array}{c}4 \\
(13.3 \%)\end{array}$ & \\
\hline \multirow[t]{2}{*}{$\begin{array}{l}\text { Self-satisfaction with } \\
\text { academic performance }\end{array}$} & No & $\begin{array}{c}87 \\
(38.8 \%) \\
\end{array}$ & $\begin{array}{c}6 \\
(6.9 \%) \\
\end{array}$ & $\begin{array}{c}44 \\
(50.6 \%)\end{array}$ & $\begin{array}{c}29 \\
(33.3 \%)\end{array}$ & $\begin{array}{c}8 \\
(9.2 \%)\end{array}$ & \multirow[t]{2}{*}{0.0001} \\
\hline & Yes & $\begin{array}{c}137 \\
(61.2 \%)\end{array}$ & $\begin{array}{c}40 \\
(29.2 \%)\end{array}$ & $\begin{array}{c}63 \\
(46 \%)\end{array}$ & $\begin{array}{c}29 \\
(21.2 \%)\end{array}$ & $\begin{array}{c}5 \\
(3.6 \%)\end{array}$ & \\
\hline
\end{tabular}

variables, including suicidal ideation, hopelessness, gender, marital status, years of education in the university, accommodation status, smoking status, and self-satisfaction with academic performance. We calculated mean and Standard Deviation (SD) for age. We used the chi-squared test to evaluate the differences between variables in terms of hopelessness and suicidal ideation. We used analysis of variances (ANOVA) test and T-test to assess the differences in participants with different severities of hopelessness and those with and without suicidal ideation in terms of age. We used logistic regression to evaluate the association between hopelessness and suicidal ideation. We considered $\mathrm{P}<0.05$ as significant. All analyses were performed using STATA software.

\section{RESULTS}

Two hundred twenty-four medical students with a mean age of $22.68(\mathrm{SD}=3.38$ ) years participated in the study (response rate $=43.32 \%)$. Eighty-four participants $(37.5 \%)$ were male, and 140 (62.5\%) were female. The demographic and educational status of participants and hopelessness based on these variables are shown in table 1.178 students (79.46\%) had mild to severe hopelessness in our study as 107 (47.76\%) had mild hopelessness, 58 (25.89\%) had moderate hopelessness, and 13 (5.8\%) had severe hopelessness. Males, senior students, and students dissatisfied with their academic performance experienced more severe types of hopelessness $(\mathrm{P}<0.05)$.

Five participants $(2.23 \%)$ had a history of attempted suicide. One had a history of using drugs, and four had a history of using stimulants from these five students. Thirtysix participants (16.07\%) had suicidal ideation. Suicidal ideation was significantly more common among smokers and those with more severe types of hopelessness $(\mathrm{P}<0.05)$. The presence of suicidal ideation in medical students based on demographic characteristics and hopelessness is shown in table 2 . The association between hopelessness and suicidal ideation is shown in figure 1.

Students with higher BHS scores were at higher risk of suicidal ideation with an unadjusted odds ratio (OR) of 1.29 (95\% confidence interval $=1.15-1.45, \mathrm{P}<0.0001)$. After adjusting for age, gender, marital status, and self-satisfaction with academic performance, the BHS score was independently associated with suicidal ideation ( $O R=1.29$, 95\% confidence interval= 1.14-1.46, $\mathrm{P}<0.0001)$. 
Table 2. Suicidal ideation in medical students based on hopelessness and demographic characteristics

\begin{tabular}{|c|c|c|c|}
\hline & $\begin{array}{l}\text { Suicidal ideation } \\
\quad(n=36)\end{array}$ & $\begin{array}{l}\text { No suicidal ideation } \\
\quad(n=188)\end{array}$ & P-value \\
\hline Age, year $(\text { Mean } \pm S D)^{*}$ & $23.27 \pm 5.77$ & $22.57 \pm 2.70$ & 0.254 \\
\hline \multicolumn{4}{|l|}{ Gender } \\
\hline Men & $10(11.9 \%)$ & $74(88.1 \%)$ & \multirow[t]{2}{*}{0.112} \\
\hline Women & $26(18.6 \%)$ & $114(81.4 \%)$ & \\
\hline \multicolumn{4}{|l|}{ Marital status } \\
\hline Married & $2(7.4 \%)$ & $25(92.6 \%)$ & \multirow[t]{2}{*}{0.062} \\
\hline Single/separated/divorced & $34(17.3 \%)$ & $163(82.7 \%)$ & \\
\hline \multicolumn{4}{|l|}{ Years of education in university } \\
\hline First/ second year & $12(15.2 \%)$ & $67(84.8 \%)$ & \multirow[t]{2}{*}{0.791} \\
\hline Third or higher & $24(16.6 \%)$ & $121(83.4 \%)$ & \\
\hline \multicolumn{4}{|l|}{ Accommodation status } \\
\hline Home & $16(17.4 \%)$ & $76(82.6 \%)$ & \multirow[t]{2}{*}{0.653} \\
\hline Dormitory & $20(15.2 \%)$ & $112(84.8 \%)$ & \\
\hline \multicolumn{4}{|l|}{ Smoking } \\
\hline No & $30(15.5 \%)$ & 164 (84.5\%) & \multirow[t]{2}{*}{0.046} \\
\hline Yes & $6(20 \%)$ & 24 (80\%) & \\
\hline \multicolumn{4}{|c|}{ Self-dissatisfaction with academic performance } \\
\hline No & $19(21.8 \%)$ & $68(78.2 \%)$ & \multirow[t]{2}{*}{0.061} \\
\hline Yes & $17(12.4 \%)$ & $120(87.6 \%)$ & \\
\hline \multicolumn{4}{|l|}{ Hopelessness } \\
\hline Normal & $2(4.3 \%)$ & $44(95.7 \%)$ & \multirow[t]{4}{*}{$<0.0001$} \\
\hline Mild hopeless & $9(8.4 \%)$ & $98(91.6 \%)$ & \\
\hline Moderate hopeless & $17(29.3 \%)$ & $41(70.7 \%)$ & \\
\hline Severe hopeless & $8(61.5 \%)$ & $5(38.5 \%)$ & \\
\hline
\end{tabular}

\section{DISCUSSION}

This study evaluated the hopelessness and suicidal ideation among TUMS medical students and investigated these two factors' association. Hopelessness was independently associated with suicidal ideation among medical students. This finding is in line with Ribeiro et al. study as they found a strong association between hopelessness and suicidal ideation, and hopelessness was the strongest predictor for suicidal ideation. There were also associations between hopelessness and suicide attempt and death due to suicide. ${ }^{29}$ Tan et al. found that hopelessness is associated with suicidality in medical students $(\mathrm{OR}=1.59, \mathrm{P}=0.034) .{ }^{30}$ As internal motivations such as hopelessness are strong predictors for suicide ideas, which is the first step toward attempting suicide, ${ }^{31}$ screening medical students regarding hopelessness may help detect at-risk students at early stages. Smoking was another factor in our study that was associated with the presence of suicidal ideation. Our finding is in line with previous studies, as smoking increases the risk of suicidal ideation independent of mood disorders. ${ }^{32,33}$ Interventions for smoking cessation in medical students may help reduce the risk of suicidal ideation and

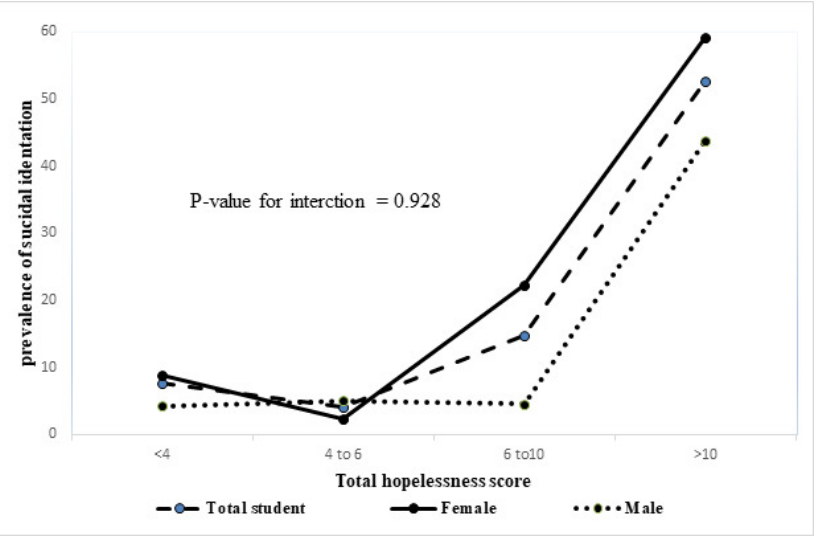

Figure 1. Association between suicidal ideation and hopelessness

suicide in this group.

In this study, $16.07 \%$ of medical students had lifelong suicidal ideation, which is in line with Khosravi et al. findings as they reported $17 \%$ of Iranian medical students. ${ }^{20} \mathrm{Al}-$ though there is a need for further studies, it seems that the 
learning environment and universities are not major contributing factors for suicidal ideation among Iranian medical students. Mohammadinia et al. evaluated the suicidal ideation among nursing, midwifery, and medical emergency students of Zahedan University of medical sciences. They found that $26.4 \%$ of these students had suicidal ideation, 19 higher than the prevalence of suicidal ideation among Iranian medical students in Khosravi et al. and our study. This contrasts with Alexandrino-Silva et al. study as they found no differences between students of different healthcare professions, including medical, nursing, and pharmacy students in Brazil. ${ }^{34}$ There may be several explanations for such a difference. First, considering the stressful nature of midwifery ${ }^{35}$ and medical emergency ${ }^{36}$ and the association between negative stress and suicidal ideation, ${ }^{37}$ may be one reason for the higher prevalence of suicidal ideation among them. Second, Tehran is much more developed than $\mathrm{Za}$ hedan. Considering the higher prevalence of suicidal ideation in people living in less developed areas and people with worth socioeconomic status, ${ }^{38}$ may be another reason for more suicidal ideation among students in Zahedan. Third, medical doctors have a significantly better future career than other health professions in Iran, leading to much hope for future success among medical students and less suicidal ideation. 39

In a systematic review and meta-analysis, Rotenstein et al. evaluated the prevalence of recent suicidal ideation among medical students, estimated to be $11.1 \%{ }^{40}$ The prevalence of suicidal ideation among our sample of Iranian medical students is relatively higher than in other countries. The higher prevalence of psychological issues may be one reason for the higher prevalence of suicidal ideas among Iranian medical students. Aghakhani et al. evaluated the prevalence of depression in a sample of Iranian medical students, and they found that $52.6 \%$ of students had some degrees of depression. ${ }^{41}$ In another study by Koochaki et al., $61.3 \%$ of Iranian medical students suffered from stress. ${ }^{42}$ The learning environment in Iranian universities and the type of relationship between the students and professors may be another reason for the high prevalence of suicidal ideation and psychological issues among Iranian medical students. The learning environment can play a role in the mental well-being of students. ${ }^{43,44}$ It seems that there is a need for interventions to reduce the prevalence of psychological issues and suicidal ideation among Iranian medical students, and studies suggest determining factors contributing to the high prevalence of these issues among Iranian medical students.

In our study, about $79.5 \%$ of medical students had mild to severe hopelessness. Those with moderate to severe hopelessness, which account for about $31 \%$ of our participants, are 11 times more likely to lose their lives due to suicide than normal people and those with mild hopelessness, ${ }^{31}$ which raises concerns regarding the high prevalence of hopelessness among Iranian medical students. In our study, hopelessness was more severe among males, senior students, and students dissatisfied with their academic performance. Budakoglu et al. found that hopelessness is more severe among medical students who are not satisfied with the city and their career selection and medical students who did not have enough information regarding medical stu- dents and preferred to choose another career rather than medicine. ${ }^{45}$ As dissatisfaction about the career choice and academic performance seems to be a predictor for hopelessness among medical students, providing enough information regarding the actual status of medicine and medical education for students before they choose to enter the medical school may be beneficial to decrease hopelessness among medicals students and prevent future mental problems leading to suicide. There is a need for interventions to reduce hopelessness among Iranian medical students considering the high prevalence of hopelessness in Iranian medical students. Also, a higher prevalence of hopelessness among senior students may indicate the learning environment's role in increasing the risk of hopelessness among medical students. Similarly, Kohoulat et al. found that a negative learning environment was associated with hopelessness in a sample of medical students of Shiraz University of medical students. ${ }^{46}$ There is a need for future studies regarding the factors in Iranian medical schools leading to hopelessness among Iranian medical students considering the association between hopelessness and subsequent suicidal ideation.

Our study was conducted as a cross-sectional study, and we can not evaluate the presence of casual relationships. As a result, future longitudinal studies are needed for assessing the factors affecting suicidal ideation among medical students. Other factors rather than hopelessness may come into play for converting ideation to action, which must be evaluated in future studies. Also, we did not assess other psychological issues such as depression, which may form suicidal ideation among medical students. Future studies with a more comprehensive evaluation of Iranian medical students' mental health and their associations with suicidal ideation are needed. The response rate was not optimal in our study too. Also, most participants were females in our study. Those who did not complete the questionnaire may have different characteristics than our sample. Future studies with larger sample sizes are indicated for better evaluation of suicidal ideation and its associated factors among Iranian medical students. Similarly, TUMS medical students, one of the top universities in Iran, experience different learning environments and may have different characteristics than other medical students in other universities in Iran. Future studies regarding suicidal ideation and its associated factors are needed to evaluate suicidality in Iranian students better.

To conclude, the prevalence of hopelessness and suicidal ideation is relatively high among Iranian medical students. As we found, hopelessness is associated with suicidal ideation among medical students, and evaluating hopelessness may be used to detect medical students at risk of suicidal ideation and future suicide. There is also a need for interventions to reduce hopelessness and suicidal ideation among Iranian medical students. Groups at high risk of hopelessness in our study, such as males and smokers, can be targeted for this purpose. 


\section{FUNDING}

This study was not funded.

\section{CONFLICT OF INTERESTS}

Authors have no conflict of interest to declare.

\section{ETHICS}

The ethical committee of TUMS approved the study protocol with the ethical code of IR.TUMS.MEDICINE.REC.1397.428IR.

Submitted: June 01, 2021 EST, Accepted: July 05, 2021 EST 


\section{REFERENCES}

1. Bachmann S. Epidemiology of suicide and the psychiatric perspective. International journal of environmental research and public health.

2018;15(7):1425.

2. Naghavi M. Global, regional, and national burden of suicide mortality 1990 to 2016: systematic analysis for the Global Burden of Disease Study 2016. BMJ. $2019 ; 364$.

3. Miron O, Yu KH, Wilf-Miron R, Kohane IS. Suicide rates among adolescents and young adults in the United States, 2000-2017. Jama. 2019;321(23):2362-2364.

4. Hassanian-Moghaddam H, Zamani N. Suicide in Iran: The facts and the figures from nationwide reports. Iranian journal of psychiatry. 2017;12(1):73.

5. Boxer PA, Burnett C, Swanson N. Suicide and occupation: a review of the literature. Journal of Occupational and Environmental Medicine. 1995;37(4):442-452.

6. Dutheil F, Aubert C, Pereira B, et al. Suicide among physicians and healthcare workers: a systematic review and meta-analysis. PloS one.

2019;14(12):e0226361.

7. Vogel L. Has suicide become an occupational hazard of practising medicine? Can Med Assoc; 2018.

8. Dyrbye LN, Thomas MR, Massie FS, et al. Burnout and suicidal ideation among US medical students. Annals of internal medicine. 2008;149(5):334-341.

9. Torres AR, Campos LM, Lima MCP, RamosCerqueira ATA. Suicidal ideation among medical students: prevalence and predictors. The Journal of Nervous and Mental Disease. 2018;206(3):160-168.

10. Dyrbye LN, Thomas MR, Shanafelt TD. Systematic review of depression, anxiety, and other indicators of psychological distress among US and Canadian medical students. Academic medicine.

2006;81(4):354-373.

11. Dyrbye LN, Harper W, Durning SJ, et al. Patterns of distress in US medical students. Medical teacher. 2011;33(10):834-839.

12. Dyrbye LN, Harper W, Moutier C, et al. A multiinstitutional study exploring the impact of positive mental health on medical students' professionalism in an era of high burnout. Academic Medicine.

2012;87(8):1024-1031.
13. Shain BN. Suicide and suicide attempts in adolescents. Pediatrics. 2007;120(3):669-676.

14. Puthran R, Zhang MW, Tam WW, Ho RC. Prevalence of depression amongst medical students: A meta - analysis. Medical education. 2016;50(4):456-468.

15. Korošec Jagodič H, Rokavec T, Agius M, Pregelj P. Availability of mental health service providers and suicide rates in Slovenia: a nationwide ecological study. Croatian medical journal. 2013;54(5):444-452.

16. Khazaei S, Armanmehr V, Nematollahi S, Rezaeian $S$, Khazaei S. Suicide rate in relation to the Human Development Index and other health-related factors: A global ecological study from 91 countries. Journal of epidemiology and global health. 2017;7(2):131-134.

17. Asghari F, Sadeghi A, Aslani K, Saadat S, Khodayari $\mathrm{H}$. The survey of relationship between perceived stress coping strategies and suicide ideation among students at University of Guilan, Iran. International Journal of Education and Research. 2013;1(11):111-118.

18. Mousavi SG, Keramatian K, Marcy MR, Fouladi M. Suicidal ideation, depression, and aggression among students of three universities of Isfahan, Iran in 2008. Iranian Journal of Psychiatry and Behavioral Sciences. 2012;6(1):47.

19. Mohammadinia N, Rezaei M, Sameizadehtoosi T, Durban F. Assessing suicidal ideation frequency in medical students. Quarterly Journal of Nursing Management. 2012;1(1):83-91.

20. Khosravi M, Kasaeiyan R. The relationship between neuroticism and suicidal thoughts among medical students: Moderating role of attachment styles. Journal of Family Medicine and Primary Care. 2020;9(6):2680.

21. Beck AT, Weissman A, Lester D, Trexler L. The measurement of pessimism: the hopelessness scale. Journal of consulting and clinical psychology. 1974;42(6):861.

22. Breier-Williford S, Bramlett RK. Time perspective of substance abuse patients: Comparison of the scales in Stanford time perspective inventory, Beck depression inventory, and Beck hopelessness scale. Psychological Reports. 1995;77(3):899-905. 
23. Dejkam N, Sharifi H, Human H. Conformity and norm of the Beck hopelessness scale among students of Tehran Islamic Azad university. Islamic Azad University Pub; 2003.

24. Yousefi N, Shirbagi N. The relationship between acceptation in MA exam with hopelessness and self-handicapping. Journal of Iranian Higher Education. Published online 2012.

25. Goldberg DP, Hillier VF. A scaled version of the General Health Questionnaire. Psychological medicine. 1979;9(1):139-145.

26. Nazifi M, Mokarami HR, Akbaritabar AK, FarajiKujerdi M, Tabrizi R, Rahi A. Reliability, validity and factor structure of the Persian translation of general health questionnaire (GHQ-28) in hospitals of Kerman university of medical sciences. Journal of Fasa University of Medical Sciences. 2014;3(4):336-342.

27. Nourbala AA, Bagheri YSA, MOHAMMAD K. The validation of general health questionnaire- 28 as a psychiatric screening tool. Published online 2009.

28. Watson D, Goldney R, Fisher L, Merritt M. The measurement of suicidal ideation. Crisis: The Journal of Crisis Intervention and Suicide Prevention. 2001;22(1):12.

29. Ribeiro JD, Huang X, Fox KR, Franklin JC. Depression and hopelessness as risk factors for suicide ideation, attempts and death: meta-analysis of longitudinal studies. The British Journal of Psychiatry. 2018;212(5):279-286.

30. Tan ST, Sherina MS, Rampal L, Normala I. Prevalence and predictors of suicidality among medical students in a public university. Med $J$ Malaysia. 2015;70(1):1-5.

31. Klonsky ED, May AM, Saffer BY. Suicide, suicide attempts, and suicidal ideation. Annual review of clinical psychology. 2016;12.

32. Clarke DE, Eaton WW, Petronis KR, Ko JY, Chatterjee A, Anthony JC. Increased risk of suicidal ideation in smokers and former smokers compared to never smokers: evidence from the Baltimore ECA follow-up study. Suicide and life-threatening behavior. 2010;40(4):307-318.

33. McGee R, Williams S, Nada-Raja S. Is cigarette smoking associated with suicidal ideation among young people? American Journal of Psychiatry. 2005;162(3):619-620.

34. Alexandrino-Silva C, Pereira MLG, Bustamante C, et al. Suicidal ideation among students enrolled in healthcare training programs: a cross-sectional study. Brazilian Journal of Psychiatry. 2009;31(4):338-344.
35. Halperin O, Goldblatt H, Noble A, Raz I, Zvulunov I, Liebergall Wischnitzer M. Stressful childbirth situations: a qualitative study of midwives. Journal of midwifery \& women's health. 2011;56(4):388-394.

36. Seyedjavadi M, Samadi N, Mohammadi R, Osmani A, Bakhtiari Kohsareh F, Seyedjavadi M. Assessment of stress in medical emergency staff in Ardabil Province, Iran. Qom University of Medical Sciences Journal. 2014;7(6):41-45.

37. Wilburn VR, Smith DE. Stress, self-esteem, and suicidal ideation in late adolescents. Adolescence. 2005;40(157).

38. Ma X, Xiang YT, Cai ZJ, et al. Lifetime prevalence of suicidal ideation, suicide plans and attempts in rural and urban regions of Beijing, China. Australian \& New Zealand Journal of Psychiatry. 2009;43(2):158-166.

39. Shaheen H, Jahan M. The role of optimism in experience of student stress and suicidal ideation. Journal of Humanities and Social Science. 2014;19(11):23-34.

40. Rotenstein LS, Ramos MA, Torre M, et al. Prevalence of depression, depressive symptoms, and suicidal ideation among medical students: a systematic review and meta-analysis. Jama. 2016;316(21):2214-2236.

41. Aghakhani N, Nia HS, Eghtedar S, Rahbar N, Jasemi M, Zadeh MM. Prevalence of depression among students of Urmia University of Medical Sciences (Iran). Iranian journal of psychiatry and behavioral sciences. 2011;5(2):131.

42. Koochaki GM, Charkazi A, Hasanzadeh A, Saedani M, Qorbani M, Marjani A. Prevalence of stress among Iranian medical students: a questionnaire survey. Eastern Mediterranean Health Journal. 2011;17(7):593-598.

43. Fekih-Romdhane F, ElKhouni C, Sassi H, Cheour $\mathrm{M}$. The role of personal factors and learning environment in suicidal ideation among Tunisian medical students. Crisis. Published online 2020.

44. Tharani A, Husain Y, Warwick I. Learning environment and emotional well-being: A qualitative study of undergraduate nursing students. Nurse Education Today. 2017;59:82-87.

45. Budakoglu Iİ, Karaoğlu N, Coşkun Ö. Loneliness, hopelessness, anxiety and self compassion of medical students: Gazi example. Gazi Medical Journal. 2014;25(4A). 
46. Kohoulat N, Hayat AA, Dehghani MR, Kojuri J,

Amini M. Medical students' academic emotions: the role of perceived learning environment. Journal of advances in medical education \& professionalism. 2017;5(2):78. 